\title{
Evidence of muscarinic acetylcholine receptors in the retinal centrifugal system of the chick
}

K.C. Calaza and
P.F. Gardino
Instituto de Biofísica Carlos Chagas Filho,

Universidade Federal do Rio de Janeiro, Rio de Janeiro, RJ, Brasil

\section{Correspondence \\ P.F. Gardino \\ Programa de Neurobiologia \\ Laboratório de Neurobiologia \\ da Retina \\ IB, CCS, UFRJ \\ 21949-900 Rio de Janeiro, RJ \\ Brasil \\ Fax: + 55-21-280-8193 \\ E-mail: gardino@ biof.ufrj.br \\ Research supported by PRO NEX- MCT, FAPERJ, FINEP, and CNPq and CEPEG (P.F. Gardino). K.C. Calaza was the recipient of a CAPES fellowship.}

Received November 6, 1998 Accepted June 16, 2000

\section{Abstract}

In this study we characterize the presence of muscarinic acetylcholine receptors (mAChR) in the isthmo-optic nucleus (ION) of chicks by immunohistochemistry with the M35 antibody. Some M35-immunoreactive fibers were observed emerging from the retinal optic nerve insertion, suggesting that they could be centrifugal fibers. Indeed, intraocular injections of cholera toxin $\mathrm{B}(\mathrm{CTb})$, a retrograde tracer, and double-labeling with M35 and CTb in the ION confirmed this hypothesis. The presence of M35-immunoreactive cells and the possible $\mathrm{mAChR}$ expression in ION and ectopic neuron cells in the chick brain strongly suggest the existence of such a cholinergic system in this nucleus and that acetylcholine release from amacrine cells may mediate interactions between retinal cells and ION terminals.

\section{Key words}

- Muscarinic receptors

- Retina

- Isthmo-optic nucleus

- Centrifugal fibers

- Acetylcholine

- Chick

\section{Introduction}

In the retina of many vertebrates there is an afferent component formed by a centrifugal projection from the brain (1). Similarly to the axons of ganglion cells which project to the contralateral optic tectum, the majority of centrifugal fibers project to the contralateral retina in chicks $(2,3)$. These retinopetal fibers originate from the caudal mesencephalic nucleus denominated isthmo-optic nucleus $(\mathrm{ION})$ and from ectopic neurons (Ecn) which are present near the ION (1). The ION terminals innervate the inferior retina and are thought to be involved in the enhancement of the visual responses of retinal ganglion cells $(1,4-6)$.

Previous reports have also suggested, however, that ION expresses features of the cholinergic system. Nickla and co-workers (7) demonstrated immunoreactivity against the alpha-7 subunit of the nicotinic acetylcholine receptor (nAChR) in centrifugal fibers and in ION neurons in chick species (7). In addition, high levels of choline acetyltransferase (ChAT) activity have been reported in homogenates of chick and pigeon mesencephalon (8). Although ChAT-immunoreactive cells were observed in the pigeon ION (9), Sorenson and co-workers (8) failed to demonstrate cholinergic cells in the chick ION. Several reports have shown evidence in the retina of such elements of the cholinergic system as ChAT $(10,11)$ and $\mathrm{nAChR}$ and muscarinic acetylcholine receptors (mAChR) (12-15), the latter including proteins and mRNAs of all three mAChR subtypes (16). Recently, immunohistochemistry 
has been used to study cellular expression of mAChR in chick retina $(17,18)$.

In a previous examination of chick retina, M35 was detected in fibers emerging from the optic nerve insertion area and ending near the amacrine cell layer (13). The aim of the present study was to determine whether these fibers are from the ION.

\section{Material and Methods}

\section{Tissue preparation}

The original research reported herein was performed under guidelines for the use of animal experimental research established by the Brazilian Society of Neuroscience and Behavior (SBNeC) and the Institute of Biophysics Carlos Chagas Filho of the Federal University of Rio de Janeiro, Brazil. Fertilized White Leghorn eggs were obtained from a local hatchery. Post-hatched animals were maintained in a free running condition with water and food ad libitum.

For retinal preparations, post-hatched animals were anesthetized with ether and then decapitated. The eyeballs were rapidly enucleated and hemisected with a razor blade, and the posterior eyecup with the retina was immersed in a fixative ( $4 \%$ formaldehyde in $0.16 \mathrm{M}$ phosphate buffer, $\mathrm{pH}$ 7.2) for $3 \mathrm{~h}$ at room temperature. Retinas were washed several times in phosphate-buffered saline (PBS) and cryoprotected with increasing concentrations of sucrose $(10,20$ and $30 \%)$. The tissue was quick-frozen in Tissue-Tek O.C.T. Compound (Sakura Finetek, Torrance, CA, USA) on dry ice, transversely sectioned at 10-15 $\mu \mathrm{m}$ on a cryostat, and collected on gelatin-coated glass slides. For brain preparations, the animals were anesthetized with an intraperitoneal injection of $200 \mu \mathrm{l}$ dialurethane $(30 \mathrm{mg} / \mathrm{kg})$ and intracardiac perfusion was performed with $200 \mathrm{ml}$ PBS, $\mathrm{pH}$ 7.4 , and then with $200-300 \mathrm{ml}$ with $4 \%$ paraformaldehyde in 0.16 M PBS, pH 7.4. Brains were dissected out and immersed in the same perfusion solution for $3 \mathrm{~h}$ at room temperature. The tissue was cryoprotected as described above, sectioned coronally at $40 \mu \mathrm{m}$, and collected in PBS.

\section{Cholera toxin injection}

The animals were first anesthetized with ether, and then a topical anesthetic (Anestalcon) was applied to the cornea. Two to five microliters of cholera toxin $\mathrm{B}(\mathrm{CTb}$; Sigma Chemical Co., St. Louis, MO, USA) at $0.5 \%(19)$ were injected intraocularly into one of the eyes using a Hamilton syringe $(50 \mu \mathrm{l})$. The survival period of the chicks was 3 to 6 days, and they were perfused as described. The ipsilateral hemisphere was used as the control for $\mathrm{CTb}$ transport since few if any ganglion cell axons in the chick retina project to the ipsilateral optic tectum (3).

\section{Immunohistochemistry}

Two commercial antibodies, mouse monoclonal antibody (M35) against mAChR (Chemunex, Paris, France) developed by André et al. (20,21) and rabbit polyclonal antibody against $\mathrm{CTb}$ (Sigma) were used. The M35 antibody indiscriminately recognizes all mAChR subtypes in mammals, indicating that the antigenic site of the $\mathrm{mAChR}$ subtypes may be highly conserved. However, there is considerable amino acid diversity in the cloned receptors from chick compared to mammalian species. Thus, in the present study all observed immunoreactivity was carefully interpreted since the presence of M35 and mAChR in chicks requires confirmation. In brain sections, all procedures were performed using free-floating incubation. Before antiserum incubation, the tissue was washed in PBS and then pretreated with $3 \% \mathrm{H}_{2} \mathrm{O}_{2}$ in PBS for $10 \mathrm{~min}$. In retinal sections, the immunohistochemical procedures were carried out on glass slides, after the retinal sections were washed in PBS. All 
antibodies were diluted in PBS plus $0.25 \%$ Triton X-100.

\section{Anti-CTb}

Brain sections were first incubated with $5 \%$ normal goat serum for $30 \mathrm{~min}$ and then incubated with rabbit anti-CTb $(1: 10,000)$ for $24-48 \mathrm{~h}$ at $4^{\circ} \mathrm{C}$. In the subsequent step, the tissue was rinsed in PBS and incubated with biotinylated goat anti-rabbit antiserum diluted 1:200 (Vector Labs, Inc., Burlingame, CA, USA) for $2 \mathrm{~h}$. After further rinsing in PBS, the brain sections were incubated with avidin-biotin complex (ABC Elite, Vector Labs) diluted 1:50 for another $2 \mathrm{~h}$. Finally, the sections were reacted with 3,3'-diaminobenzidine tetrahydrochloride $(0.1 \mathrm{mg} / \mathrm{ml})$ in $0.1 \mathrm{M}$ Tris buffer, $\mathrm{pH} 7.2$, plus $0.01 \%$ hydrogen peroxide solution or alternatively with the SG Kit substrate (Vector Labs). The ipsilateral hemispheres showed no CTb staining.

\section{Anti-M35}

The sections were incubated for $30 \mathrm{~min}$ in 5\% normal goat serum followed by overnight incubation with mouse anti-mAChR diluted 1:400 (M35). We then performed the $\mathrm{ABC}$ method as described for $\mathrm{CT}$. Sections incubated in the absence of primary antibodies were used as immunohistochemical control. No immunoreactivity was observed in the control sections.

\section{Double-labeling}

Double-immunostaining for M35 and $\mathrm{CTb}$ was carried out using a procedure similar to that described above. Briefly, CTb labeling was performed using a biotinylated anti-rabbit IgG followed by the avidin-biotin complex and reacted with the SG Kit substrate. In order to visualize the M35-positive cells, the brain sections were incubated with biotinylated anti-mouse IgG (Sigma) diluted
1:20 for $2 \mathrm{~h}$. After several washes with PBS, the brain sections were incubated overnight with Cy3-conjugated streptavidin (Sigma) diluted 1:200. These sections were mounted with $0.2 \mathrm{M} \mathrm{N}$-propyl-gallate in phosphate buffer plus $40 \%$ glycerol and the doublelabeled cells were examined under an Axioskop fluorescent microscope (Zeiss, Jena, Germany).

\section{Results}

\section{M35 expression in the $10 \mathrm{~N}$}

The immunohistochemical staining of M35 in the retina coincides with previous findings of mAChRs in the chick retina $(17,18)$ and surprisingly revealed intensely immunolabeled fibers in the optic nerve insertion and optic fiber layer (OFL) crossing the ganglion cell layer (GCL) and inner plexiform layer (IPL) and ending near the amacrine cell layer (Figure 1b). Nevertheless, it was impossible to determine whether the fibers were afferent, efferent, or intrinsic processes. Part of this intense labeling may have been due to processes from ganglion cells since M35 is expressed in this cell type (18). However, in our preparations some fibers located close to the amacrine cell layer of the retina and running parallel to the IPL (Figure 1c) were observed. These transverse fibers were similar to those described as centrifugal fibers from the ION in chick retina (22). This finding suggests that cells of the ION could be expressing M35.

In order to determine whether ION and Ecn cells express M35, free-floating coronal brain sections at the caudal mesencephalic level were immunostained for M35. Labeling was detected in several nuclei at this level (data not shown) including several cell bodies in the ION and Ecn (Figure $2 b$ and $d$ ). This result suggests that M35-positive fibers in the optic nerve insertion and at the OFL could be retinopetal fibers and might indeed originate from ION and Ecn cells. 
Double-labeling for the M35 antibody and the retrograde transporter $\mathrm{CTb}$ confirmed that ION and Ecn projection express putative mAChRs. In addition to cell bodies immunolabeled only for CTb and M35 (Figure 3 ), cells double-labeled for CTb and M35 were also found (Figure 2). The doublelabeled cells therefore project to the contralateral eye, and may be the source of M35immunoreactive fibers that appear to enter the retina.

The ION and Ecn cells are generated between the fifth and seventh embryonic day (E5-7) $(23,24)$ and later undergo natural cell death from E13 to E16 $(24,25)$. However, centrifugal fibers reach the retina on day E9 and the system is anatomically complete on day E12 (25). To determine whether the M35 retinal efferent develops as the total ION afferent, the ontogenetic pattern of M35 immunoreactivity was examined.

On E9, M35 immunoreactivity was observed only in cell bodies located in the

Figure 1 - Photomicrographs of retinal sections labeled with mAChR. Arrows in a (embryonic day 14 - E14) and in b and C (postnatal - PN) show presumably centrifugal immunoreactive fibers against mAChRs. ON stands for optic nerve and OFL for optic fiber layer. In a and C, the arrowhead points to an $\mathrm{mAChR}$ cell soma. Scale bars $=$ $20 \mu \mathrm{m}$.

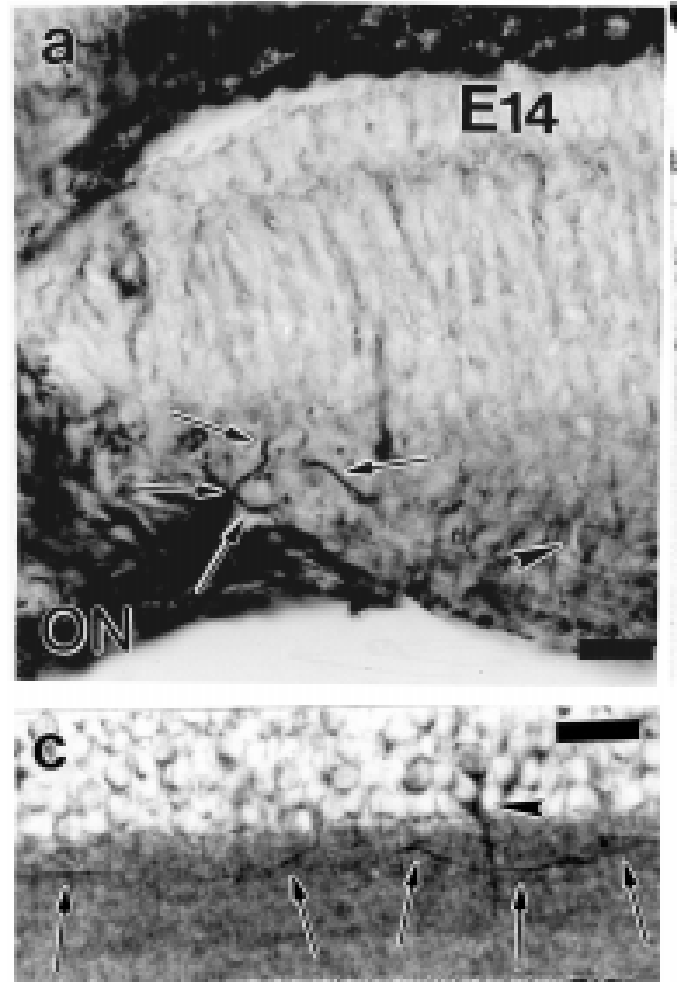

innermost third of the inner nuclear layer (INL) and in the GCL of the retina (13). At this stage, the INL is composed of neuroblastic and differentiated cells, whereas in the GCL, ganglion cells have already ended their differentiation. Although centrifugal fibers reach the retina (25), no immunoreactivity was found in the optic nerve region. On E14, fibers in the optic nerve insertion running through the OFL could be clearly observed in addition to labeling in the OFL (Figure 1a).

\section{Discussion}

\section{M35 in presumptive centrifugal fibers}

The avian ventral retina receives substantial inputs from the ION and Ecn cells, particularly onto associational amacrine cells (1). The dorsal retina, in turn, projects to the contralateral optic tectum from which relay fibers project to the ION. Therefore, the

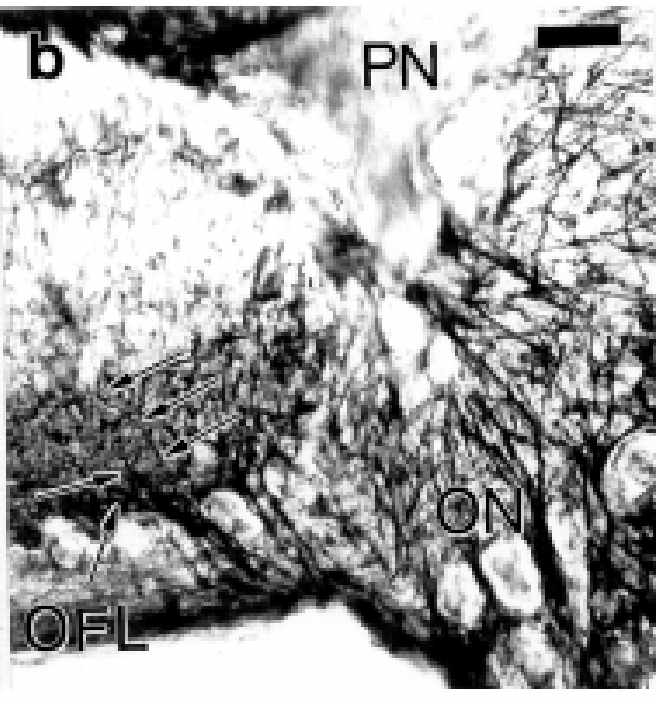


pathway comprises a closed loop from ganglion cells in the dorsal retina to the tectum, to ION, to amacrine cells in the ventral retina, and back to ganglion cells in the dorsal retina $(1-6,26,27)$.

In the present study, M35-positive fibers
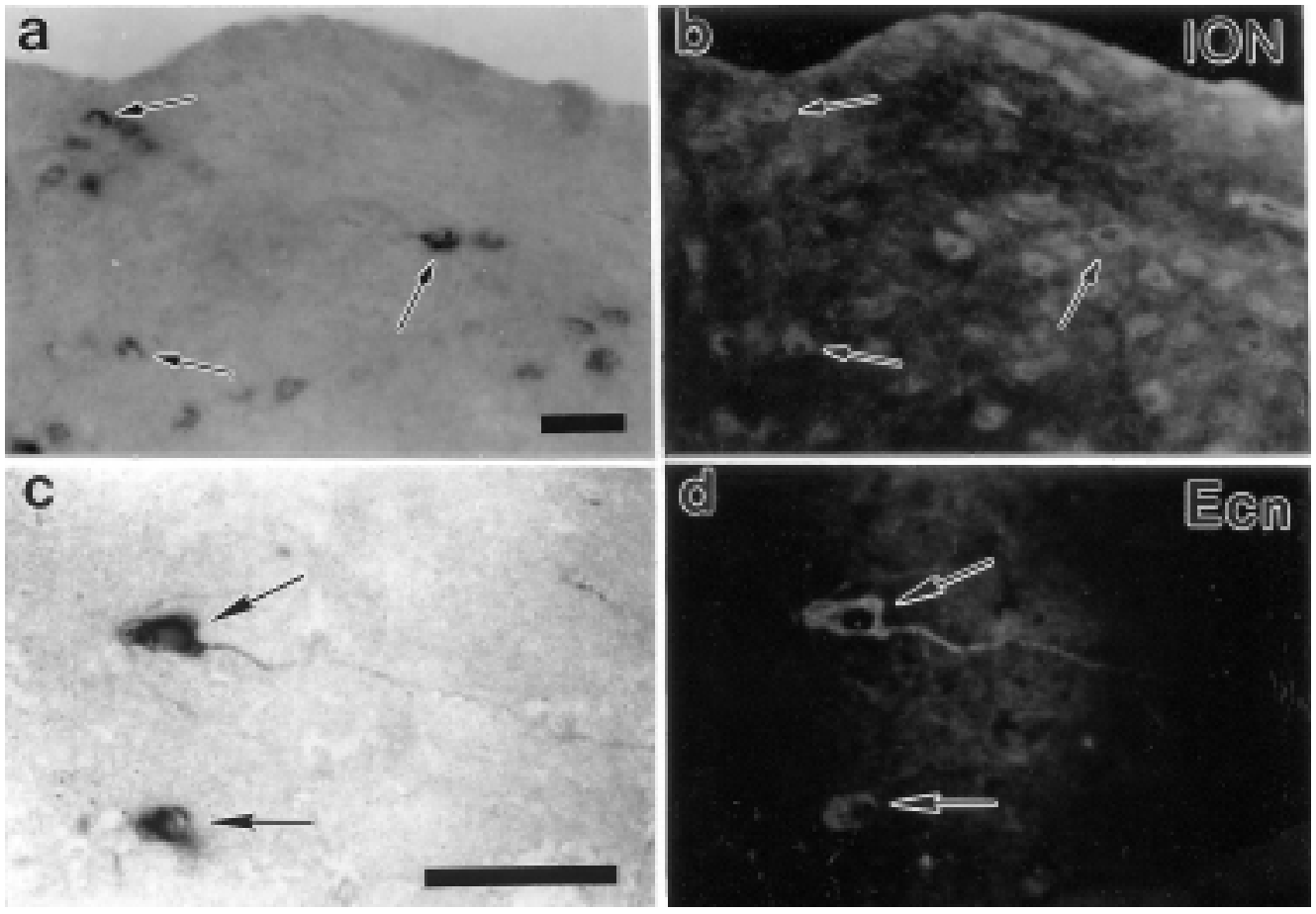

Figure 2 - Photomicrographs of chicken brain sections at the mesencephalic level. Arrows point at the isthmo-optic nucleus (ION) (a) and ectopic neuron (Ecn) (c) cholera toxin-immunoreactive cells. In $b$ and $d$, $\mathrm{mAChR}$ expression is observed in the same cells as in a and $c$. Scale bars $=20 \mu \mathrm{m}$.
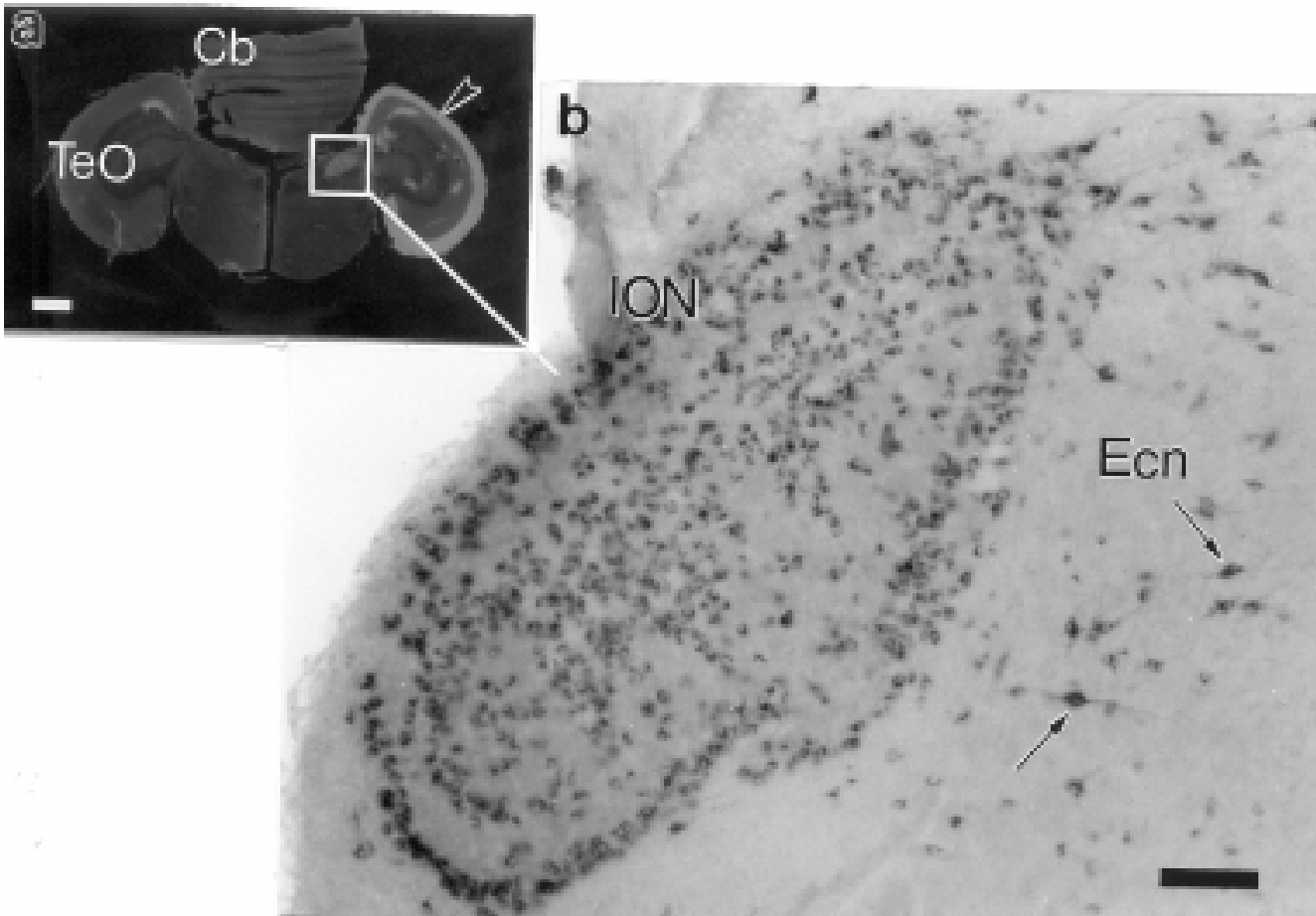

Figure 3 - Photomicrographs of chicken brain sections at the mesencephalic level. a, Negative of a photomicrograph of a coronal section. $\mathrm{Cb}$ - Cerebellum, TeO - tectum opticum, and ION - isthmo-optic nucleus (white square) amplified in b. The arrowhead points at the contralateral immunoreactivity against cholera toxin in the stratum opticum and stratum griseum et fibrosum superficiale of the $\mathrm{TeO}$, and the scale bar indicates $1 \mathrm{~mm}$. Panel b shows cholera toxin immunoreactivity in both ION and ectopic neuron (Ecn) (arrows) cells. The scale bar indicates $100 \mu \mathrm{m}$. 
were observed for the first time at the emergence of the optic nerve, entering through the OFL and reaching the INL in retinas from E14 to post-hatched animals. This result shows that M35 expression in putative centrifugal fibers occurs in the retina after E12 when innervation of the retina by ION and Ecn cells is complete (25).

In order to confirm the idea that M35 is present in centrifugal fibers, we doublestained the ION cell bodies for M35 and CTb that had been injected into one of the eyes. The presence of cell bodies in ION which were double-labeled for $\mathrm{CTb}$ and M35 is consistent with the idea that retinopetal fibers express M35.

In spite of extensive anatomical and electrophysiological studies on neurotransmitter systems of the chicken retina and of the ION, those that are functional in this nucleus have not been identified. Suggestions come from the work of Morgan et al. (28), who have demonstrated that ION terminals contain high levels of histochemically detectable NADPHdiaphorase activity, and from Blute et al. (29), who have demonstrated double-labeling of NADPH-diaphorase and nitric oxide synthase in presumptive retina efferents in the turtle retina. In addition, Paes de Carvalho and co-workers (30) have localized NADPHdiaphorase in the chick retina.

Taken together, these data suggest that ION neurons may use nitric oxide as a modulator $(28,29)$. Therefore, it is possible that acetylcholine released from retinal cells activates presumptive $\mathrm{mAChRs}$ present presynaptically in ION terminals, thus modulating nitric oxide synthesis. This, in turn, may affect ganglion cells that respond to ION activation, altering receptive field properties and, consequently, the ganglion cell response $(6,31)$. Bagnoli and co-workers (9) reported that there are ChAT-positive ION cells in pigeons, suggesting that the acetylcholine receptors in the ION presynaptic terminals could modulate their own process of acetylcholine release. The presence of M35-im- munoreactive cells and the possible mAChR expression in ION and Ecn cells in the chick brain strongly support the existence of such a cholinergic system in this nucleus and suggest that acetylcholine may mediate interactions between retinal cells and ION terminals. However, it should be noted that Sorenson and co-workers (8) did not find any ChAT-immunoreactive cells in the chick ION.

Centrifugal fibers coming from the ION and from ectopic neurons project exclusively into the ventral retina in birds (1-3). The distribution of some catecholaminergic cells is coincident with retinal targets of the ION (32). Moreover, cells involved in long proprioretinal connections are found in the ventral retina of chicks (22). These systems may enhance the light sensitivity of the retina at the expense of its sensitivity to contrast $(1,4-$ 6,31 ), or may be involved in a system for switching the attention between either half of the visual field under partial control of retinopetal fibers (1). Acetylcholine is released from amacrine cells in the retina upon light stimulation (33) and therefore, under photopic conditions, may modulate ION terminal activity. One possibility could be that presumptive centrifugal fibers make conventional synapses en passant onto cholinergic processes, which branch in sublaminae 2 and 4 of the IPL (11) before reaching the final target close to the INL. Another possibility is that acetylcholine released from amacrine cell processes in sublaminae 2 and 4 of the IPL diffuses to layers closer to the INL, reaching M $35 / \mathrm{mAChR}$ at the ION terminals.

Our data show that in chicks, M35 immunoreactivity is present in ION and Ecn cell bodies and perhaps in the centrifugal fiber terminals in the retina. These results suggest that acetylcholine can modulate the output of centrifugal fibers in the retina by acting on presynaptic mAChRs. It is important to emphasize, however, that the identity of M35immunoreactive substances has not been fully 
established, and therefore the role of this substances in the retinopetal circuit remains to be clarified.

In this study we utilized the anti-mAChR antibody, M35 (20,21), that recognizes mAChR subtypes mainly in mammals, and mouse receptors have $75 \%$ homology with chick receptors. However, M35 labeling found in our previous study data (13) matches Nathanson's $(17,18)$ results with specific $\mathrm{mAChR}$ antibodies in the chick retina. In addition, our preliminary immunoblot results showed an immunolabeled band close to the molecular weight protein described for mAChRs (data not shown). Thus, we suggest that M35-immunoreactive cells in the ION and Ecn could be indicative of the presence of mAChRs in some cells of this nucleus. It is important to emphasize that the functional aspects of these receptors in ION and Ecn and in the centrifugal fibers in the retina remain to be clarified.

\section{Acknowledgments}

We thank Mair M.M. de Oliveira and Rosilane Taveira da Silva for technical assistance. The helpful comments of Drs. Jan Nora Hokoç and Marília Z.P. Guimarães are greatly appreciated.

\section{References}

1. Uchiyama H (1989). Centrifugal pathways to the retina: influence of the optic tectum. Visual Neuroscience, 3: 183-206.

2. Cowan WM (1970). Centrifugal fibers to the avian retina. British Medical J ournal, 26: 112-118.

3. Crossland WJ , Cowan WM, Rogers LA \& Kelly J P (1974). The specification of the retino-tectal projection in the chick. J ournal of Comparative Neurology, 155: 127164.

4. Hayes BP \& Holden AL (1983). The distribution of centrifugal terminals in the pigeon retina. Experimental Brain Research, 49: 189-197.

5. Woodson W, Shimizu T, Wild JM, Schimke J, Cox K \& Karten HJ (1995). Centrifugal projections upon the retina: an anterograde tracing study in the pigeon (Columba livia). J ournal of Comparative Neurology, 362: 489-509.

6. Miles FA (1971). Centrifugal effects in the avian retina. Science, 170: 992-995.

7. Nickla DL, Gottlieb MD, Marin G, Rojas X, Britto LRG \& Wallman J (1994). The retinal targets of the centrifugal neurons and the retinal neurons projecting to the accessory optic system. Visual Neuroscience, 11: 401-409.

8. Sorenson EM, Parkinson D, Dahl JL \& Chappinelli VA (1989). Immunohistochemical localization of choline acetyltransferase in the chicken mesencephaIon. J ournal of Comparative Neurology, 281: 641-657.

9. Bagnoli $P$, Fontanesi $G$, Alersci $R \&$ Erichsen J T (1992). Distribution of neu- ropeptide $\mathrm{Y}$, substance $\mathrm{P}$, and choline acetyltransferase in the developing visual system of the pigeon and effects of unilateral retina removal. J ournal of Comparative Neurology, 318: 392-414.

10. Shen SC, Greefield P \& Boell EJ (1956). Localization of acetylcholinesterase in chick retina during histogenesis. J ournal of Comparative Neurology, 106: 433-461.

11. Spira AW, Millar TJ, Ishimoto I, Epstein $M L$, J ohnson CD, Dahl J L \& Morgan IG (1987). Localization of choline acetyltransferase-like immunoreactivity in the embryonic chick retina. J ournal of Comparative Neurology, 260: 526-538.

12. Sugiyama $H$, Daniels MP \& Nirenberg $M$ (1977). Muscarinic acetylcholine receptors of the developing retina. Proceedings of the National Academy of Sciences, USA, 74: 5524-5528.

13. Calaza KC \& Gardino PF (1996). Muscarinic receptor immunoreactive cells in the chick retina. Society for Neuroscience Abstracts, 22: 1756.

14. Hamassaki-Britto DE, Gardino PF, Hokoç J N, Keyser KT, Karten HJ , Lindstrom J M \& Britto LRG (1994). Differential development of $\alpha$-bungarotoxin-sensitive and $\alpha$ bungarotoxin-insensitive nicotinic acetylcholine receptors in the chick retina. J ournal of Comparative Neurology, 347: 161170.

15. Keyser $K T$, Hughes TE, Whiting PJ, Lindstrom J M \& Karten HJ (1988). Cholinoceptive neurons in the retina of the chick: an immunohistochemical study of the nicotinic acetylcholine receptors. Vis- ual Neuroscience, 1: 349-366.

16. McKinnon LA \& Nathanson NM (1995). Tissue-specific regulation of muscarinic acetylcholine receptor expression during embryonic development. J ournal of Biological Chemistry, 270: 20636-20642.

17. Fischer AJ , McKinnon LA, Nathanson NM \& Stell WK (1998). Identification and localization of muscarinic acetylcholine receptors in the ocular tissues of the chick. J ournal of Comparative Neurology, 392: 273-284.

18. McKinnon LA, Gunther EC \& Nathanson NM (1998). Developmental regulation of the $\mathrm{cm} 2$ muscarinic acetylcholine receptor gene: selective induction by a secreted factor produced by embryonic chick retinal cells. J ournal of Neuroscience, 18: 5969.

19. Mikkelsen J D (1992). Visualization of efferent retinal projections by immunohistochemical identification of cholera toxin subunit B. Brain Research Bulletin, 28: 619-623.

20. André C, Guillet J C, Debacker J P, Vanderheyden $P$, Hoebeke J \& Strosberg AD (1984). Monoclonal antibodies against the native or denatured forms of muscarinic acetylcholine receptors. EMBO J ournal, 3: 17-21.

21. André $C$, Marullo S, Guillet J , Convents $A$, Lawereys M, Kaveri S, Hoebeke J \& Strosberg AD (1987). Immunochemical studies of the muscarinic acetylcholine receptor. J ournal of Receptor Research, 7: 89-103.

22. Catsicas S, Catsicas M \& Clarke PGH 
(1987). Long-distance intraretinal connections in birds. Nature, 326: 186-187.

23. Cowan WM \& Powell TPS (1962). Centrifugal fibers in the avian visual system. Proceedings of the Royal Society of London, 158: 232-252.

24. O'Leary DMD \& Cowan WM (1982). Further studies on the development of the isthmo-optic nucleus with special reference to the occurrence and fate of ectopic and ipsilaterally projecting neurons. J ournal of Comparative Neurology, 212: 399-416.

25. Clarke PGH \& Cowan WM (1976). The development of the isthmo-optic tract in the chick with special reference to the occurrence and correction of developmental errors in the location and connections of isthmo-optic neurons. J ournal of Comparative Neurology, 167: 143-164.

26. Woodson W, Reiner A, Anderson $K \&$
Karten HJ (1991). Distribution, laminar location, and morphology of tectal neurons projecting to the isthmo-optic nucleus and the nucleus isthmi, pars parvocellularis in the pigeon (Columba livia) and chick (Gallus domesticus): a retrograde labelling study. J ournal of Comparative Neurology, 305: 470-488.

27. Maturana HR \& Frenk S (1965). Synaptic connections of the centrifugal fibers of the pigeon retina. Science, 150: 359-362.

28. Morgan IG, Miethke P \& Li ZK (1994). Is nitric oxide a transmitter of the centrifugal projection in avian retina? Neuroscience Letters, 168: 5-7.

29. Blute TA, Mayer B \& Eldred WD (1997). Immunocytochemical and histochemical localization of nitric oxide synthase in the turtle retina. Visual Neuroscience, 14: 717-729.

30. Paes de Carvalho R, Faria MH, Nasci- mento J LM \& Hokoç J N (1996). Development of NADPH-diaphorase in the avian retina: regulation by calcium ions and relation to nitric oxide synthase. J ournal of Neurochemistry, 67: 1063-1071.

31. Miles FA (1972). Centrifugal control of the avian retina. I. Receptive field properties of retinal ganglion cells in the isthmo-optic nucleus. Brain Research, 48: 65-92.

32. Dos Santos RM \& Gardino PF (1998). Differential distribution of a second type of tyrosine hydroxylase immunoreactive amacrine cell in the chick retina. J ournal of Neurocytology, 27: 33-43.

33. Masland RH \& Livingstone CJ (1976). Effect of stimulation with light on synthesis and release of acetylcholine by an isolated mammalian retina. J ournal of Neurophysiology, 39: 1210-1219. 